\title{
Development and research of the cultivator frame design made of non-standard beams
}

\author{
Viktor Telegin* and Igor Telegin \\ Lipetsk State Technical University, Lipetsk, Russia
}

\begin{abstract}
The paper presents the results of the development and study of the strength of the cultivator frame made of non-standard beams. The term "non-standard beam" refers to a off-sized beam welded from steel strips. As such stripes, both standard hot-rolled strips and strips cut from standard cold-rolled or hot-rolled sheets can be used. The main advantage of the proposed frame design is the relatively low cost and availability of materials for its manufacture, as well as the potential to minimize the weight of the finished product by changing the thickness and dimensions of the strips used. Frame design and calculations were performed by the Autodesk Inventor Professional environment.
\end{abstract}

\section{Introduction}

When designing any engineering product, along with its operability, special attention is paid to cost and, often directly related to it, metal consumption $[1,2,3]$. The main indicator of a product's performance is its strength $[4,5]$, for the assessment of which the safety factor is used. Along with the strength indicators of the product's elements, their performance depends on the magnitude of elastic and plastic deformations, dynamic and static processes that arise during the product's work $[6,7]$.

The calculation of the safety factor can be performed by methods of strength of materials $[1,2]$. However, these methods, in the general case, are rather laborious and do not differ in accuracy. At present, the finite element method (FEM) $[8,9,10]$ is most often used to model the elastic-deformable state of an object. Combined with solid modeling, FEM (and its modifications) is the foundation of modern design.

In this work, Inventor Professional is used to calculate the frames of cultivators [11, 12]. This is one of the most famous software products that joined methods of solid modeling, design documentation development, strength and dynamic calculations based on FEM.

\section{The basic design of the cultivator and the formulation of the research problem}

Figure 1 shows a 3D model of the cultivator basic design, the frame of which is made of square $(80 \times 80 \times 6)$ and rectangular $(80 \times 60 \times 6)$ standard tubes.

* Corresponding author: vv.telegin@yandex.ru 


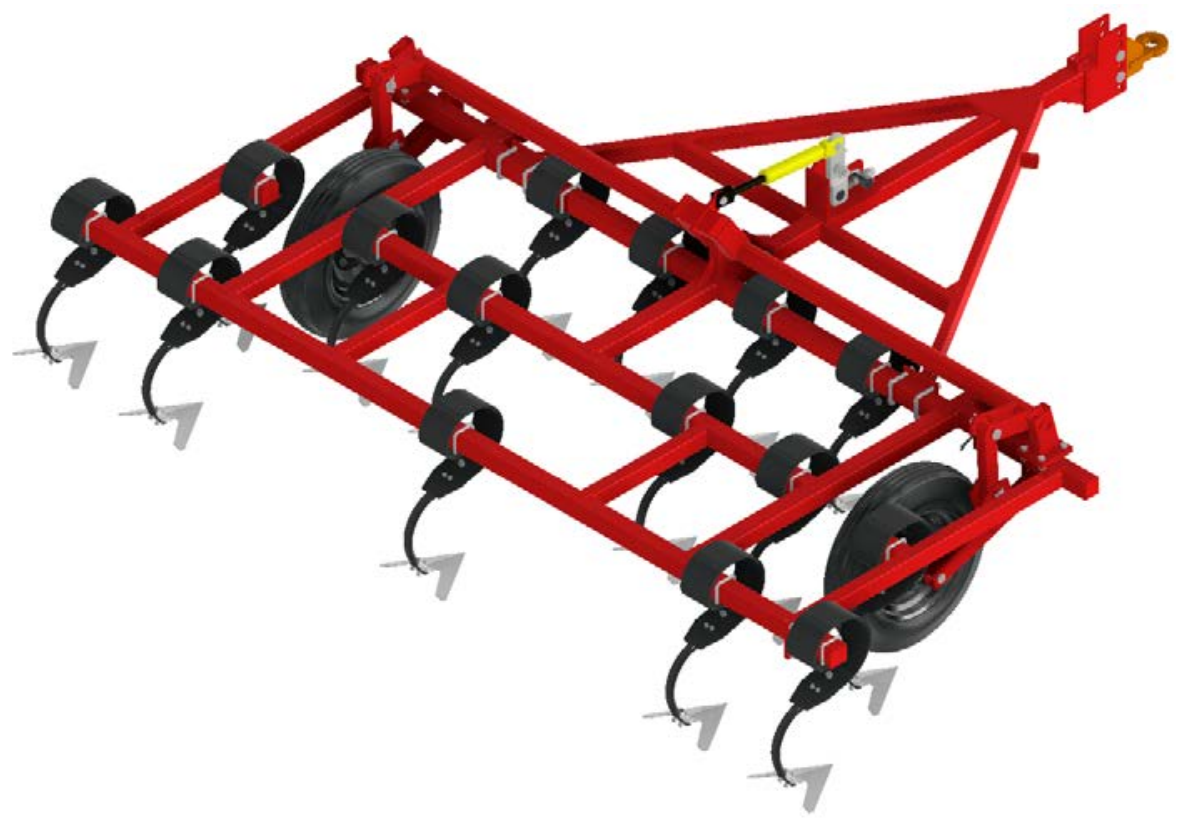

Fig. 1. 3D model of the cultivator. Basic design.

Directly the object of research and construction is its frame. Figure 2 shows a 3D model of the cultivator frame basic structure and a diagram of the external forces application and restrictions on the movement of its elements.

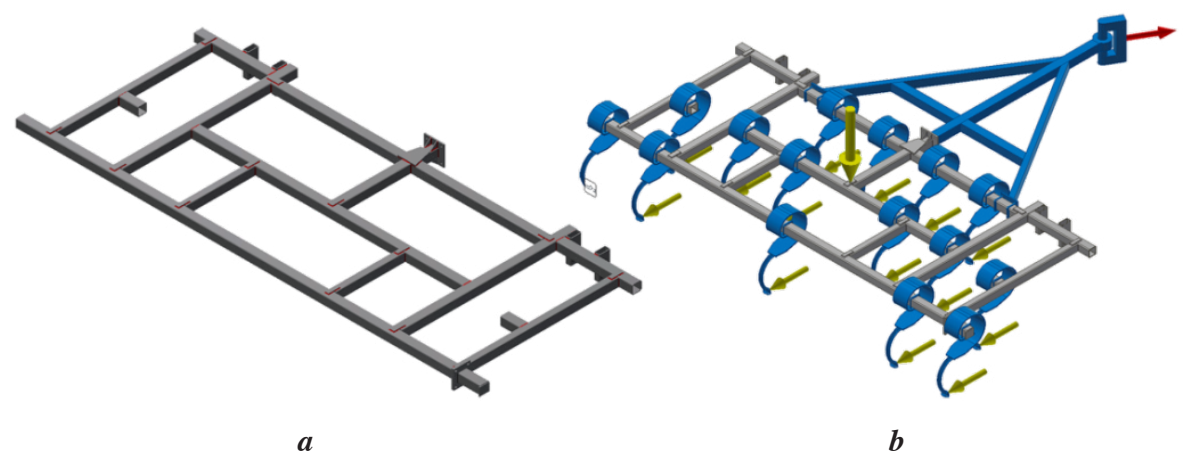

Fig. 2. 3D model of the cultivator frame. Basic structure: $a$ - welded frame, $b$ - diagram of the forces application in the strength study.

At the preliminary stage of the study, several schemes of loading the cultivator frame were considered. As a result, a loading option was established that does not contradict the recommendations of the manufacturer of this cultivator model, at which the safety factor of the frame is minimal (Figure 2b). According to this variant, the frame is under the influence of gravity, pulling force from the side of the "hitch tongue" $(60 \mathrm{kN}$, angle of application $\left.30^{\circ}\right)$ and forces acting on the suspension from the soil during their movement $(3 \mathrm{kN})$.

Suspension's paw (far left) is fixed and motionless. The force is applied to the "hitch tongue", the last element of which can only move in the horizontal plane and only in the direction of the force. All other paws are affected by forces of the same magnitude. In this study, the value of the pulling force is assumed to be overestimated. Its real value ranges from 18 to $27 \mathrm{kN}$. 
Figure 3 shows a fragment of the cultivator frame (basic design) with the minimum calculated values of the safety factor.
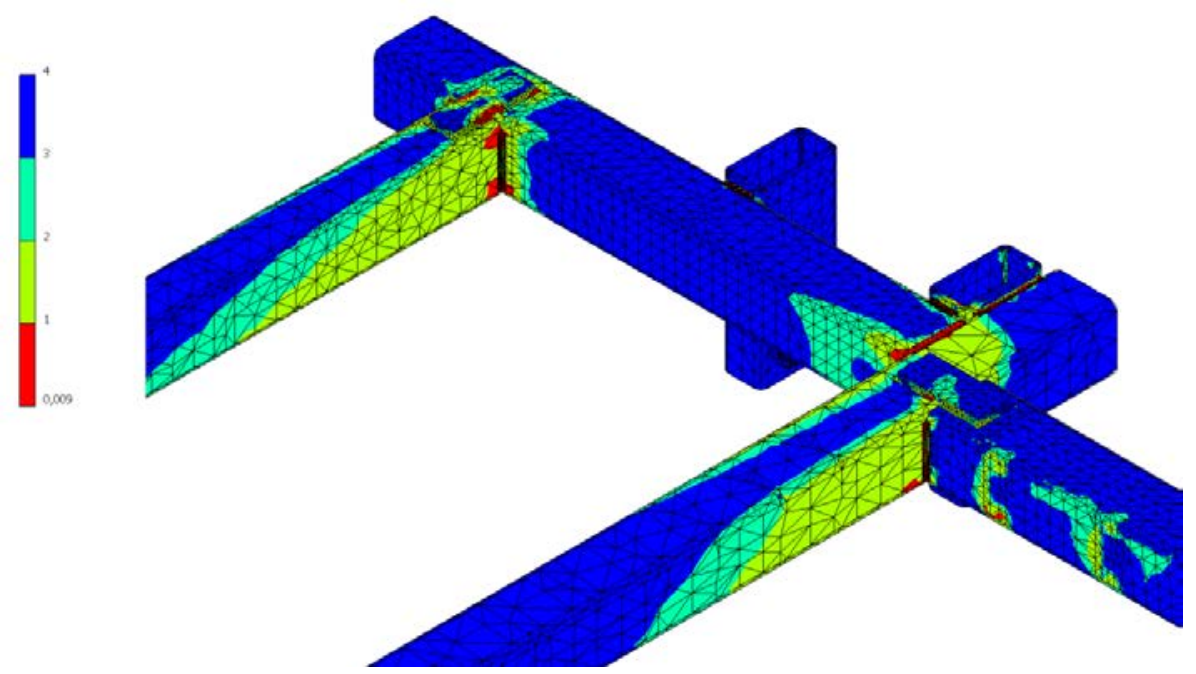

Fig. 3. Calculation of safety factor.

The safety margin of the cultivator frame basic structure, with the exception of individual fragments of beams, significantly exceeds the required one, which makes it possible to predict the abbility its modernization in order to reduce the metal consumption. The exception, at first glance, is welds. This is due to the peculiarity of frame computational model, during the development of which the influence of its parts on each other is excluded. The connection is carried out only through the beads of the welds. This feature of the model allows you to identify problem areas associated with joining parts by welding. The overestimated value of the pulling force allows to additionally localize problem areas of the beam fragments.

The research objective is to create a $3 \mathrm{D}$ model of a workable cultivator frame made of beams representing welded structures of steel strips. An example of such a beam is shown in Figure 4.

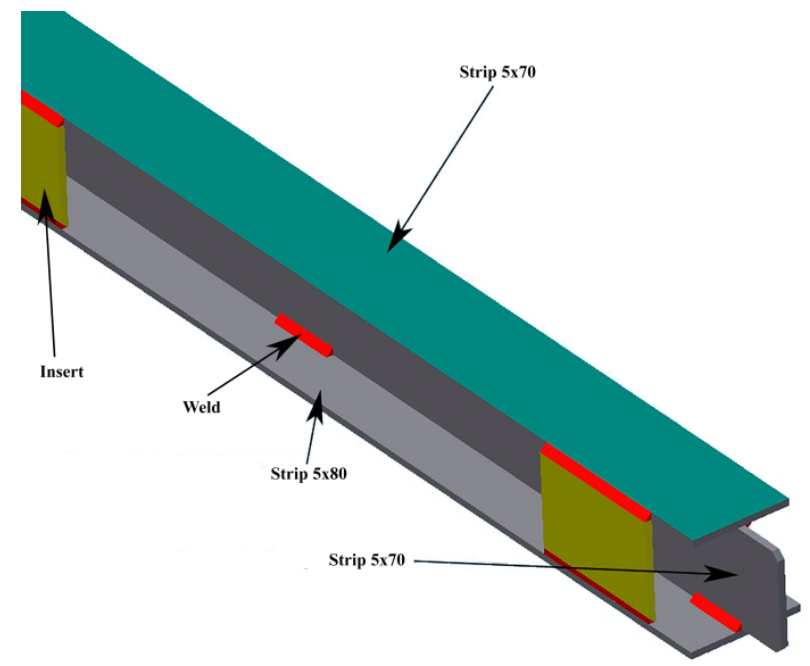

Fig. 4. Cultivator frame with non-standard beam design. 


\section{Cultivator frame construction made of non-standard beams}

Figure 5 shows a 3D model of the cultivator frame (initial design stage) made of nonstandard beams.
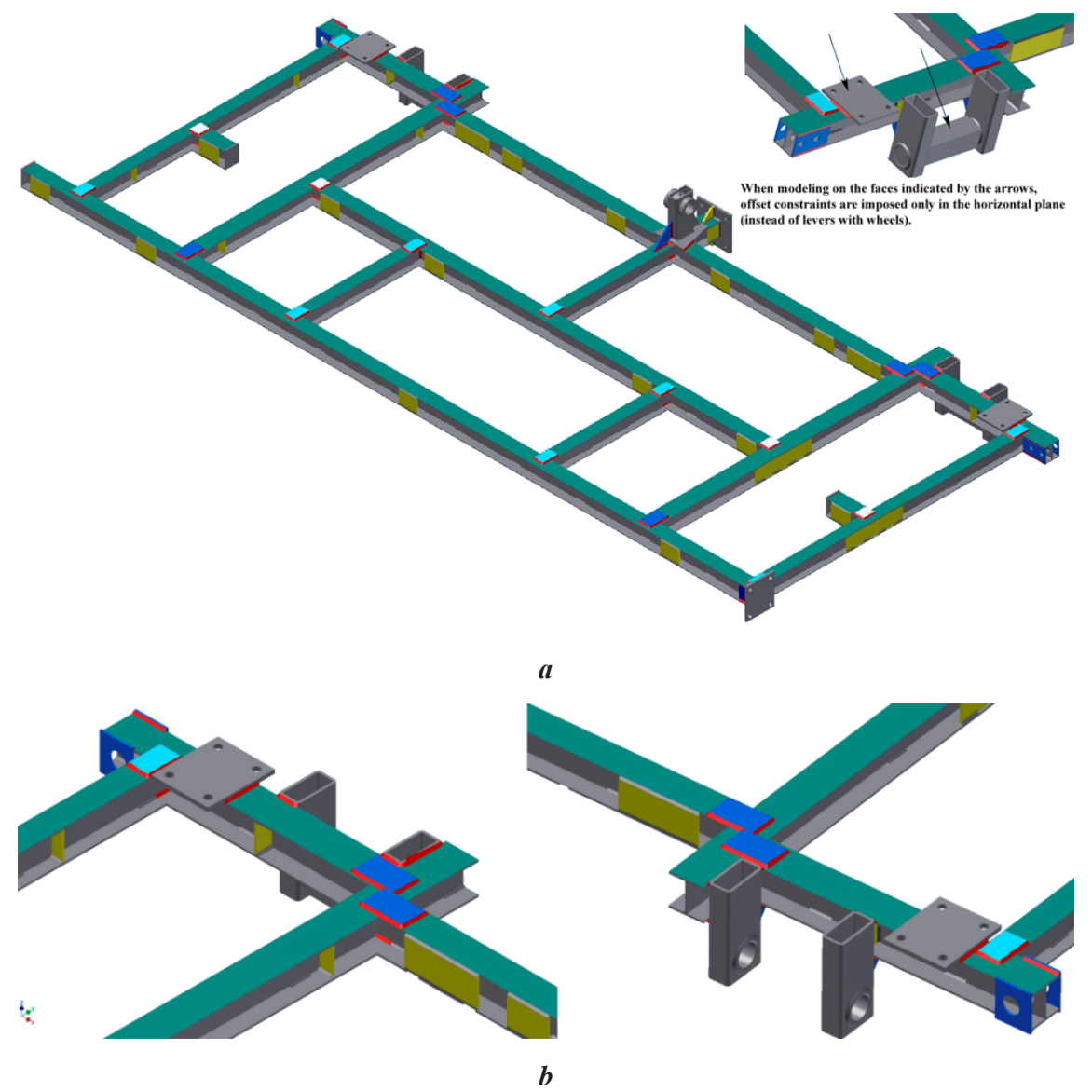

Fig. 5. The initial stage of designing a 3D model of the cultivator frame: $a$ - frame, $b$ - fragment of frame.

Figures 6 and 7 show the results of calculating the safety factor of problematic (requiring revision) fragments of the cultivator frame structure. The calculation scheme is shown in Figure 2.
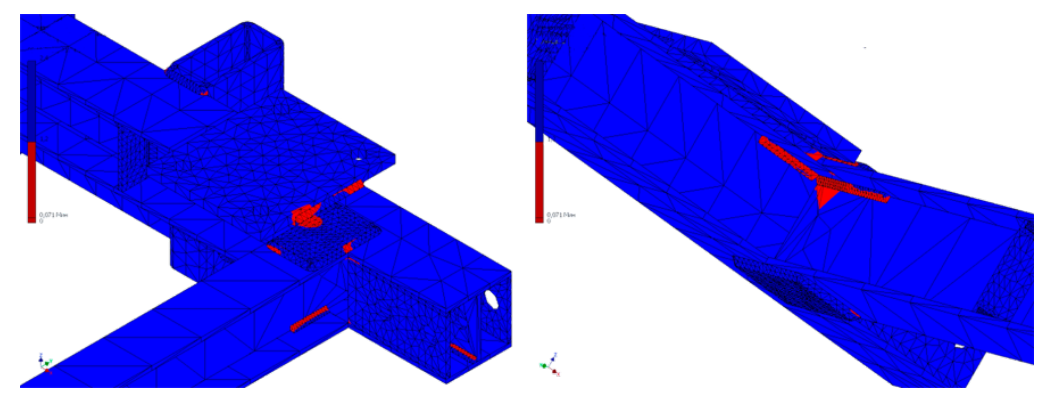

Fig. 6. Calculation of the cultivator safety factor: problematic fragments in the frame structure. Top views. 


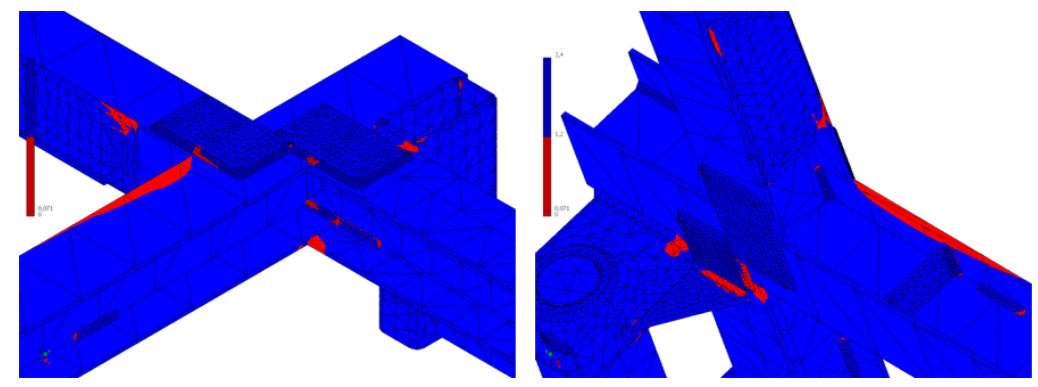

Fig. 7. Calculation of the cultivator safety factor: problematic fragments in the frame structure. Bottom views.

\section{Modification of the cultivator frame design}

The results of numerical modeling presented in Figure 6 showed the presence of problem areas in cultivator frame design with minimum values of the safety factor. It should be borne in mind that with a real pulling force $(27 \mathrm{kN}$ instead of $60 \mathrm{kN})$, the safety factor is higher than one (these calculation results are not included in the article). With the aim of further improvement, changes were made to the design of the cultivator frame. Additional inserts have been added in problem areas (Figure 8).

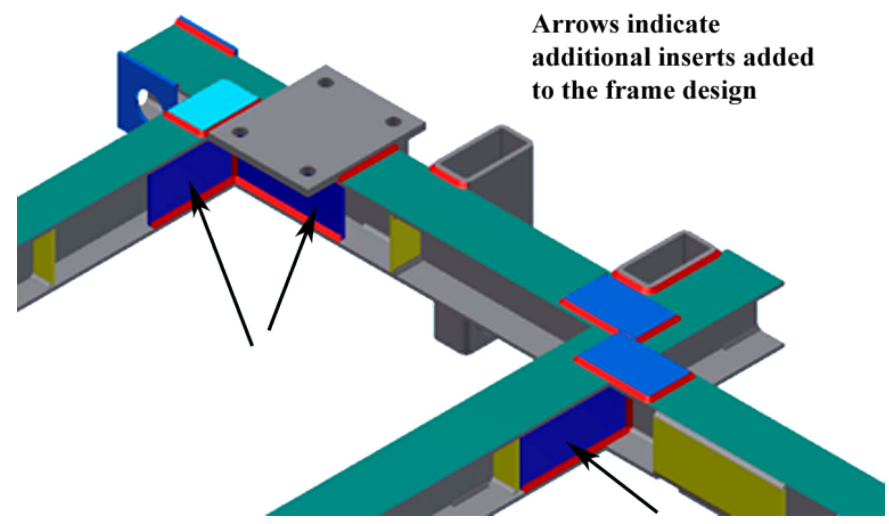

Fig. 8. Redesign of the cultivator frame.

The calculation results for the improved frame design are shown in Figure 9.

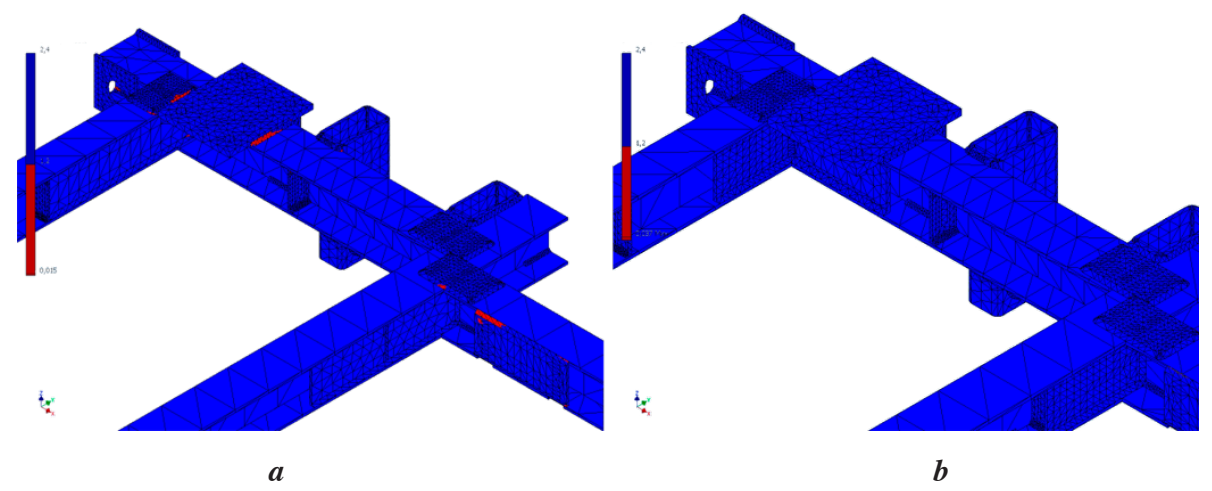

Fig. 9. Safety factor calculation of the improved cultivator frame. Pulling force: $a-60 k N, b-27 k N$. 
At the final stage of the structure operability analysis, the rigidity assessment was made. The results are shown in Figure 10.

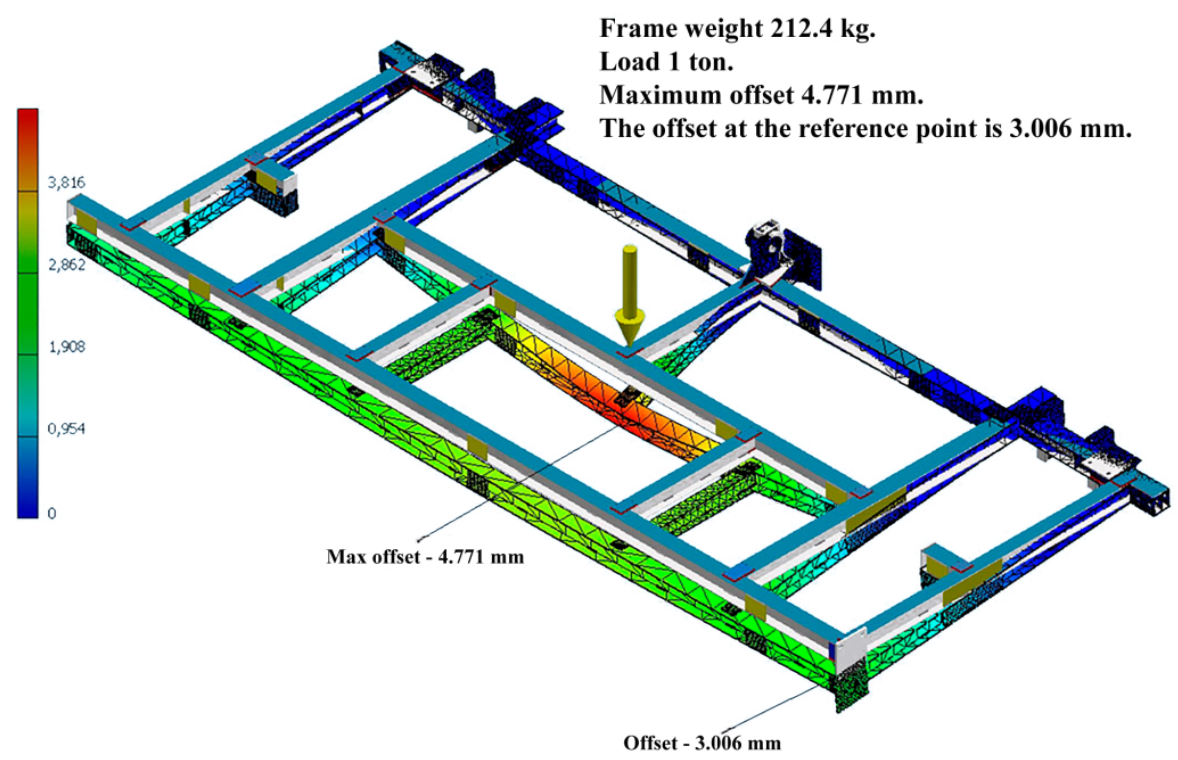

Fig. 10. The stiffness calculation results of the improved cultivator frame design.

Research has shown (Figure 10) that the rigidity of the new frame design is $37 \%$ less than the base design. The displacement of frame elements with several meters dimensions by an amount of $3-5$ millimetres under the load that is almost five times its weight is quite acceptable.

\section{Conclusion}

The method of designing welded frame structures in Autodesk Inventor Professional guarantees both high productivity of design work and their quality. This article demonstrates the capabilities of this program to optimize the designed structures of mechanical engineering objects. So in this particular case, it was possible to develop a new cultivator frame design in terms of strength that is not inferior to the base frame model with a weight of $21.4 \%$ less. The weight of the base frame model is $270.5 \mathrm{~kg}$. The weight of the new frame is $206.5 \mathrm{~kg}$.

The results of the developments presented in this article are used in the educational process [13, 14, 15], implemented at the Department of Mechanical Engineering Technology of Lipetsk State Technical University, in training personnel for engineering enterprises.

\section{References}

1. A.N. Ustinov, Agricultural Machines: 2nd Edition (Moscow: IRPO "Academy", 2010)

2. B.G. Turbina, Agreecultural machines. Agreecultural equipment. Theory and technological calculation (Moscow: Mechanical Engineering, 2007) 
3. E.S. Bosoy, O.V. Vernyaev, I.I. Smirnov, E.G. Sultan-Shah, Theory, Design and Calculation of Agricultural Machines: A Textbook for High Schools of Agricultural Engineering (Moscow: Mechanical Engineering, 1977)

4. I.A. Birger, B.F. Shorr, G.B. Iosilevich, Strength analysis of machine parts: Handbook, 4th ed., Revised (Moscow: Mechanical Engineering, 1993)

5. P.F. Dunaev, O.P. Lelikov, Construction of units and parts of machines: Textbook. allowance for tech. spec. universities (Moscow: Higher school, 1998)

6. V.V. Telegin, A.M. Kozlov, V.I. Sakalo, Solid Modeling and Dynamic Analysis of Mechanisms of Press-forging Machines, Procedia Engineering, v. 206, pp. 1258-1263 (2017)

7. V. Telegin, A. Kozlov, T. Shumilova, Development and research of the rotating lever object as a dynamic model of a cycle mechanism, MATEC Web Conf. International Conference on Modern Trends in Manufacturing Technologies and Equipment (ICMTMTE 2018), v. 224, pp. 02078 (2018)

8. V.A. Ovcharenko, Calculation of mechanical engineering problems by the finite element method: Textbook (Kramatorsk: DGMA, 2004)

9. R. Gallagher, The Finite Element Method. The basics (Moscow: Mir, 1984)

10. O.C. Zienkiewicz, The finite element method in engineering science (Moscow: Mir, 1975)

11. D.V. Zinoviev, Design Fundamentals in Autodesk Inventor 2016, 2nd ed. (Moscow: DMK Press, 2016)

12. V.G. Kontsevich, Solid State Modeling of Engineering Products in Autodesk Inventor (Moscow: DMK Press, 2007)

13. V.V. Telegin, I.V. Telegin, A.V. Kirichek, Solid-state modeling and basic training of specialists in the field of mechanical engineering, IOP Conf. Ser.: Mater. Sci. Eng., v. 483, pp. 012004 (2019)

14. V.V. Telegin, I.V. Telegin, A.S. Stepanov, 3D-Forming and Autodesk Autocad at the Initial Stage of Engineering Training of Specialists in Technical Areas, International Journal of Engineering and Technology (UAE), v. 7(3.5), pp. 1-3 (2018)

15. V.V. Telegin, I.V. Telegin, Solid Modeling in Professional Training of Specialists for Machine-Building Enterprises, International Journal of Innovative Technology and Exploring Engineering (IJITEE), v. 8(9S3), pp 7-9 (2019) 